\title{
\$sciendo
}

Ethics \& Bioethics (in Central Europe), 2020, 10 (3-4), 173-178

DOI:10.2478/ebce-2020-0015

\section{Axiological justification of the objective norm by Heinrich Rickert}

\begin{abstract}
Aleksander Bobko ${ }^{1}$
Abstract

The aim of this paper is to show the main thesis concerning the theory of cognition of the eminent neo-Kantian Heinrich Rickert, as presented in his work "Der Gegenstand der Erkenntnis". On the one hand, Rickert finds out that thinking is fated to "clash with nothingness", thus creating a temptation to reject all rigours and to yield to complete discretion. On the other hand, he attributes axiological status to nothingness which subjects thinking to a particular kind of "ought". In his view, the cognizing subject is faced with an axiological choice: either discretion or truth and argues that it is worth opting for truth. His argumentation could be an interesting point of reference for contemporary culture gradually moving away from the type of thinking rooted in objectively existing principles.
\end{abstract}

Keywords: Heinrich Rickert, values, objectivity, norm

\section{Introduction}

It cannot be denied that contemporary culture has undermined the foundations of the traditionally understood objectivity of science, cognition and thinking itself. This is all the more interesting since some philosophical schools like pragmatism or postmodernism regard it as a positive change. For Richard Rorty, the inability to appeal to truth and the abandonment of claims to objective cognition is not a fault but, on the contrary, an advantage of human thought. This, he argues, makes it possible to remove restraints of, de facto apparent, rigour and create a non-committal community based on mutual sympathy and solidarity, permeated by freedom and methodological nonchalance. The expectations with regard to science and scientists have also changed: "The image of the great scientist would not be of somebody who got it right but of somebody who got it new. A scientist would rely on a sense of solidarity [... ] rather than on the picture of herself as battling through the veils of illusions, guided by the light of reason" (Rorty, 1991, p. 44).

Practical effects of moving away from rigourism can be seen in everyday experience: in the quality of discourse in the public space and in the lines of argumentation concerning significant ethical dilemmas. This is aptly described by Alasdair MacIntyre:

The most striking feature of contemporary moral utterance is that so much of it is used to express disagreements; and the most striking feature of the debates in which these disagreements are expressed is their interminable character. I do not mean by this just that such debates go on and on and on- although they do - but also that they apparently can find no terminus. There seems to be no rational way of securing moral agreement in our culture (MacIntyre, 2007, p. 6).

The question arises, therefore, as to whether it still makes sense to strive for the justification of the objectivity of norms to which our thinking should be subjected?

\footnotetext{
${ }^{1}$ University of Rzeszow (Poland); bobkoale@ur.edu.pl; ORCID 0000000306096982
} 


\section{Rickert's theory of judgement}

To answer this question I will refer to the book "Der Gegenstand der Erkenntnis" written over 100 years ago by one of the leading neo-Kantians, Heinrich Rickert. In my opinion, his approach to cognition may still be interesting and instructive. On the one hand, he points out that reasoning is doomed to clash with emptiness (even with nothingness), generating some kind of blank space which creates a temptation to reject all rigours in favour of absolute discretion. On the other hand, he attributes a distinct status to nothingness in which man (a thinking subject) is faced with an axiological choice: either discretion or truth, with a whole raft of arguments underpinning the truth. At the beginning of his inquiry into the essence of cognition Rickert states:

The concept of cognition embraces, apart from the subject or the I which cognizes, the object which is being cognized. The notion of the object does not involve anything else but what is vis-à-vis the subject as something independent of him and to which cognition should adapt [sich danach richten] in order to achieve its aim. The aim of cognition is for it to be true and objective. Our question is: what is the object, independent of the subject, as the measure of cognition or, how does cognition acquire its objectivity? (Rickert, 1928, p. 1).

These sentences are the gist of the further account of the concept of cognition and problems relating to it. Rickert justifies his way of addressing the issue as follows: "There must exist something that is independent of the experiencing subject in the way that cognition, to become true and objective, adapts to it. Otherwise, raising an epistemological question to which a true answer is expected does not make sense. This presupposes an absolute difference between true and false and also something that reinforces this difference. True or cognitive thinking is always something more than a subject's pure thinking. It is this <more $>$ that constitutes objectivity" (Rickert, 1928, p. 8).

Therefore, before delving into the problems of cognition, we must either presuppose the existence of a true and objective form of cognition (i.e., true is distinguishable from false), or we agree to accept skepticism which, in fact, involves the equivalence of all statements. For Rickert it is obvious to opt for the first, as only then intellectual activities make sense. Thus, the aim of his scrutiny is to clarify how cognition is possible (assuming that such a possibility exists). This leads to the question of what is basically the difference between true and false?

The key to finding an answer to this question is judgment analysis as, in Rickert's view, the process of making judgements is central to human cognition. In his judgement theory, Rickert refers to Kant but the same time argues with him and goes beyond his concept.

According to Kant, "All judgments are accordingly functions of unity among our representations" (Kant, 1998, p. A69, B94). This unity, to put it briefly, is generated by understanding, whose functioning - contrary to sensible experience which is only able to feel passive sensations - is characterized by spontaneity. Spontaneity of intellectual reasoning has its own structure based on functions, understood as follows: "By a function, however, I understand the unity of the action of ordering different representations under a common one. Concepts are therefore grounded on the spontaneity of thinking" (Kant, 1998, pp. A68, B93). Thus, understanding introduces order, grasping several representations by one, more general representation constituting a notion. The final result of such a function of understanding is judgement, in which the synthesis of what is contained in representations takes place. This synthesis is of a very complicated nature and Kant devoted to it a good deal of his analyses in "The critique of pure reason".

According to Rickert, if we adopt Kant and his followers' approach, "making judgements seems to be closely related to representation (vorstellungsmäßiges Gebilde), and with this assumption 
everything stays the same - the truth of judgement must be inherent in representations" (Rickert, 1928, p. 148). This makes it impossible to base cognition on a transcendent measure. Issuing judgements should be, in a new way, open to truth - "While making judgements, apart from the relations among representations' elements, another element comes into play which, however, cannot be understood as something connected with representation" (Rickert, 1928, p. 167). This new element that a cognitive act adds to the representations perceived involves "either affirming or denying" (Rickert, 1928, p. 184). What is meant by this?

While explaining the role of affirming, Rickert directs our attention to the most relevant, in his view, moment of a cognitive act. The need to take a decision, to pronounce the affirming "yes' or negating "no", puts the cognizing subject in front of an alternative, the sui generis "either - or". This situation forces the subject to engage, to adopt a definitive stance, excluding a purely contemplative character of the act. This description cannot be interpreted from a psychological point of view, implying that there is an emotional relationship between the cognizing subject and the object cognized. What is involved here is something more fundamental, which has no connection with emotions or psychic experiences, but which makes the subject adopt a stance towards values - "The very act of issuing judgment as affirming or denying, according to its sense, should be given equal standing with the attitude adopted towards a positive or negative value (Stellungsnahme zu einer Wert oder Unwert)" (Rickert, 1928, p. 185). Thus, it turns out that a cognitive act becomes an act of evaluation, therefore cognition must relate to the sphere of values.

The question which arises about the nature of the relationship between reality and values introduces us to the most original part of Rickert's philosophy - his theory of value. He writes: "We already know that the notion of being is not the only notion to which something can be subdued, alongside it, apart from non-something or nothing there is an all-embracing notion of something non-existent, the notion of values. We use this word [...] to denote forms which do not exist but in spite of this they are something" (Rickert, 1928, p. 260). In this statement there appears an intuition implying that reality itself is not enough to know it thoroughly. What exists in reality does not necessarily express the richness of being. Thus, to encompass it fully one needs to refer to something non-existing or existing in a different way from that of reality and which, in this sense, is unreal. To define this unreal sphere Rickert proposes the term "value".

Is this not a case of "multiplying entities without necessity"? It would seem that values are found in "real" reality as well. Real objects exist, called goods, which are intrinsically connected with values such as works of art, goods meeting people's needs, also people themselves. They could all be called values. There are also acts of valuing where values are assigned to particular objects or persons thereby becoming "more real". These examples show that although there is a certain relationship between reality and values, they are not the same. Rickert claims that "goods (Güter) and acts of valuing (Wertungen) are not values, but a relation between values and reality. Values constitute a realm for themselves (Reich für sich)" (Rickert, 1928, p. 195), so putting them on the same footing as real entities would lead to overlooking their substance. How, then, can we determine their nature? Rickert answers: "The best way to express the nature of values is to say that they are valid (gelten)" (Rickert, 1928, p. 260). Values are valid, they are relevant and that is why they have [a] specific nature as compared with existing reality.

Establishing a distinction between reality and values - between being (Sein) which exists and that which doesn't exist, but which is valid (Gelten) is not an original idea of Rickert's. In his theory he exploits the notion of "the reality of what is valid" (Lotze, 1928, p. 514) introduced by Herman Lotze who characterizes the sphere of validity as follows: 
We shouldn't ask what validity is, assuming that what is meant by it can be drawn still from something else. [...] Just as we cannot say how it happens that something is or something takes place, similarly not much can be explained with regard to the fact that truth is valid. We must see in validity the basic concept which relies entirely on itself and everybody knows how to understand it (Lotze, 1928, p. 512).

Both validity and being are primary notions which, similarly to axioms in mathematics, cannot be defined although we understand their meaning.

How is validity reflected in acts of judgements, what is the relation between values and the measure of cognition for which we search and on which true cognition and objectivity rely? Rickert writes: "in every act of judgement, in a blink of an eye (Augenblick), in which I affirm, I assume that I recognize in it something that is timelessly valid and entirely independent of my temporary, actual, psychological state" (Rickert, 1928, p. 198). Let us focus on the paradoxical nature of the above description. What has been affirmed while issuing judgement, that is the value underpinning the judgement's argument, as it is towards this value that the cognizing subject adopts a particular stance, is characterized by incredible fragility and transience. It lacks a firm foundation in reality, it is only present "in the blink of an eye". On the other hand, value has an astonishing potential exceeding the scope of reality. Its paramount importance manifests itself in the fact that it is universally and timelessly valid.

\section{Thinking according values}

What results from the fact that issuing a judgement means adopting an approach towards the valid value? Rickert writes: "The state of certainty or, more exactly, the value about which this state informs me and which I affirm, grants my act of judging a character of unconditional necessity" (Rickert, 1928, p. 199). Two moments can be distinguished in the relation between the act of judging and value. The first one is of subjective character: the presence of value induces in the cognizing subject a mental state which could be called a sense of evidence. However, unconditional necessity of judgement is not based on this evidence, it is founded on the validity of unreal values. The other moment of the above-mentioned relationship consists in a direct transfer of necessity from the unreal sphere of values to a real judgement. Rickert states: "This necessity, which consolidates each act of judgement and thereby each act of cognition should be defined as the necessity of judgement (Urteilsnotwendigkeit). This is the best conceptual description; power (Macht) on which we depend while affirming" (Rickert, 1928, p. 236). The validity of values, the unreal structure of meanings inherently connected with necessity (called Urteilsnotwendigkeit by Rickert), is the foundation of true cognition. A subject perceiving the elements belonging to the real world is dependent in the act of judging on the "power" resulting from the validity of unreal values. Paradoxically, the unreal shapes the real.

This mysterious impact of values and their validity (i.e. their timeless relevance) on the acts of cognition cannot be understood as a sui generis "mechanical" process. "The necessity of judgement" is not the reason which makes a judgement issued in reality true. It is not simple coercion inducing in the cognizing subject a state which determines him directly to acknowledge value. It is a kind of imperative which requires subduing - "What makes my act of judging justified is the responsibility guaranteed by the necessity of judgement (durch Urteilsnotwendigkeit verbürgte Sollen) which I should, in a confirmative way, acknowledge" (Rickert, 1928, p. 201). The relationship between real cognition and valid values - interdependence of the sphere of being and unreal values - are best expressed by the notion of ought (Sollen). The domain of values which 
is valid regardless of the existing reality creates the sphere of ought, which is what should be acknowledged in the act of cognition by the cognizing subject.

Let us look at the asymmetry of the relation between these spheres. The unreal ought has a significant effect on the perception of reality. It requires acknowledging, some kind of respect which occurs in the act of cognition. What is real, however, does not have any effect on the sphere of ought - value is valid regardless of being acknowledged in the cognitive act or not; ought does not gain any additional strength resulting from its acknowledgement by the cognizing subject. That is why value which is to be acknowledged in the act of judging (and this is what the act of judging and thereby the act of cognition consist in) is, in view of this act, transcendent.

This brings us to the solution of the problem which Rickert considered to be fundamental for the theory of cognition. The transcendent measure of cognition for which we search is found in the unreal, valid value and, in ought, related to it. On the one hand, the valid value and its vibrant strength of ought become present in the act of judgement - they appear to the cognizing subject at least for "a blink of an eye"- but although they are made aware this way, they stay completely independent of the cognizing subject and do not become part of his immanent world. Values are valid regardless of the fact whether their validity has been acknowledged in the act of cognition or not - "It is enough for the judging subject to be aware of the ought because it can only be assumed as independent of acknowledged as being transcendentally valid, i.e., as remaining beyond judgement [urteilsjenseitig], but not beyond consciousness" (Rickert, 1928, p. 236). To put it briefly - "what is" has no influence on "what ought to be". Thereby, ought remains entirely transcendent as regards the cognizing subject.

Following Rickert's train of thought we can formulate the conclusion - the final determination of the measure of cognition: "If cognition is affirming, its measure is what is being affirmed whereas what the act of judging affirms and acknowledges, always remains in the sphere of ought, never in the sphere of real being" (Rickert, 1928, p. 214). Transcendentally valid value which works by means of ought, constitutes the relevant, independent of the subject, object of cognition. It is a measure whereby cognition is associated with truth and objectivity which is a condition of acquiring a reasonable knowledge of reality.

It must be emphasized that Rickert views the nature of values in a radically non-object way. Values are not objects which can be experienced, their essence lies in validity. On the other hand, the main motive of Rickert's theory of cognition is searching for the object of cognition something that being a measure of cognition is in front of the cognizing subject. And this is the measure that he looks out for in the sphere of valid values. How, then, can this approach be reconciled with the non-object character of values? In what way truth, not being an object, is to stand vis-à-vis the subject?

For Rickert, overcoming this controversy is possible thanks to the fact that the relationship connecting the thinking subject with value possesses an axiological character. The use of the term "axiological relationship" is justified here owing to the way in which Rickert characterizes the essence of this relationship: "each value must relate to the subject in such a way that it becomes ought for it" (Rickert, 1928, p. 337). Describing the way in which value "stands in front of" the subject, Rickert refers to the notion of ought on which, in his opinion, this relationship is based. The notion indicates the "non-ontological" nature of the relationship between thinking and truth truth does not exert influence by presenting itself, but by generating ought. Thinking is "bound" by necessity which "not -is" but is valid. Truth as value carries unusual power - it subordinates thinking using a means which is beyond the sphere of being. Ought is such a means. It addresses the subject in a different way than something standing, vis-à-vis, to him, it doesn't tell the subject "you should". Rather, it expresses a kind of "one should" which, representing universal rationality, 
demands respect. By the same token, value by means of ought is incorporated into the structure of thinking which, in turn, becomes "thinking according values". 2

\section{Conclusion}

Thus, implicit at the source of thinking is some axiological decision, thinking is based, using Rickert's phrase, on an original act of adopting a stance towards values. It may prove to be a stance towards nothingness. Yet this nothingness, as Rickert insists, is relevant, it emanates the power of ought and commits thinking to rigour.

It is just this message that seems to be of particular importance for contemporary culture. Given the methodological and logical "nonchalance" thinking should impose rigour on itself even if nothingness should be its source. Heinrich Rickert says the foundation of this rigourism is of axiological character - it is noticeable via ought, which appeals to us and which obliges us to rigourous thinking. We do not have to yield to ought but if this is the case, thinking diffuses in the space of complete discretion and latitude. Depending on the mood of the moment, this space may turn out to be friendly or hostile.

\section{References}

KANT, I. (1998): Critique of pure reason, trans. P. Guyer \& A. Wood. Cambridge: Cambridge University Press.

LOTZE, H. (1928): Logik. Leipzig: Meiner.

MACINTYRE, A. (2007): After virtue. Notre Dame: University of Notre Dame Press.

RICKERT, H. (1928): Der Gegenstand der Erkenntnis. Tübingen: Mohr Verlag.

RORTY, R. (1991): Objectivity, relativism and truth. Cambridge: Cambridge University Press.

TISCHNER, J. (1982): Myślenie wedtug wartości [Thinking in values]. Kraków: Znak.

\footnotetext{
${ }^{2}$ The idea of "thinking according values" develops in very interesting way polish philosopher Józef Tischner (Tischner, 1982).
} 